\title{
Chronic tophaceous gout: Unique presentation in a Bulgarian patient!
}

\author{
Ivanka Temelkova $^{1}$, Jose Carlos Cardoso ${ }^{2}$, Georgi Tchernev ${ }^{1^{*}}$ \\ ${ }^{1}$ Onkoderma-Clinic for Dermatology, Venereology and Dermatologic Surgery \\ ${ }^{2}$ University Hospital of Coimbra, Portugal
}

Received: September 27, 2019; Accepted: September 27, 2019; Published: September 30, 2019

*Corresponding author: Prof. Dr. Georgi Tchernev, Onkoderma-Clinic for Dermatology, Venereology and Dermatologic Surgery General Skobelev 26, 1606 Sofia, GSM: 00359885588424 e-mail:georgi_tchernev@yahoo.de

We present a 47 year old man, complaining about the appearance of solid oval formations in the area of the elbows and right hand with about one year duration (fig. 1a-d). The patient has a metabolic syndrome. According to the anamnestic data, the patient had suffered from gouty tophi in the past and has been treated for gout, but at the time of the examination in the clinic he was completely asymptomatic. Radiography and histologic examination has been performed in an orthopedic ward with a conclusion for gouty tophi. During the dermatological examination, solid, nodular lesions were found in the area of the two elbow joints (fig. 1a-b). A formation of the same character was also visualised at the base of the thumb on the right hand (fig. 1c-d). Paraclinical data were indicative for the presence of dyslipidemia. There was no evidence of an acute gout attack. Based on clinical, anamnestic and laboratory findings, it was concluded that it is a patient with tophaceous gout affecting the elbow joints and the base of the right thumb. There were no available data for renal complications. Performance of surgical correction has been planned in an orthopedic department.
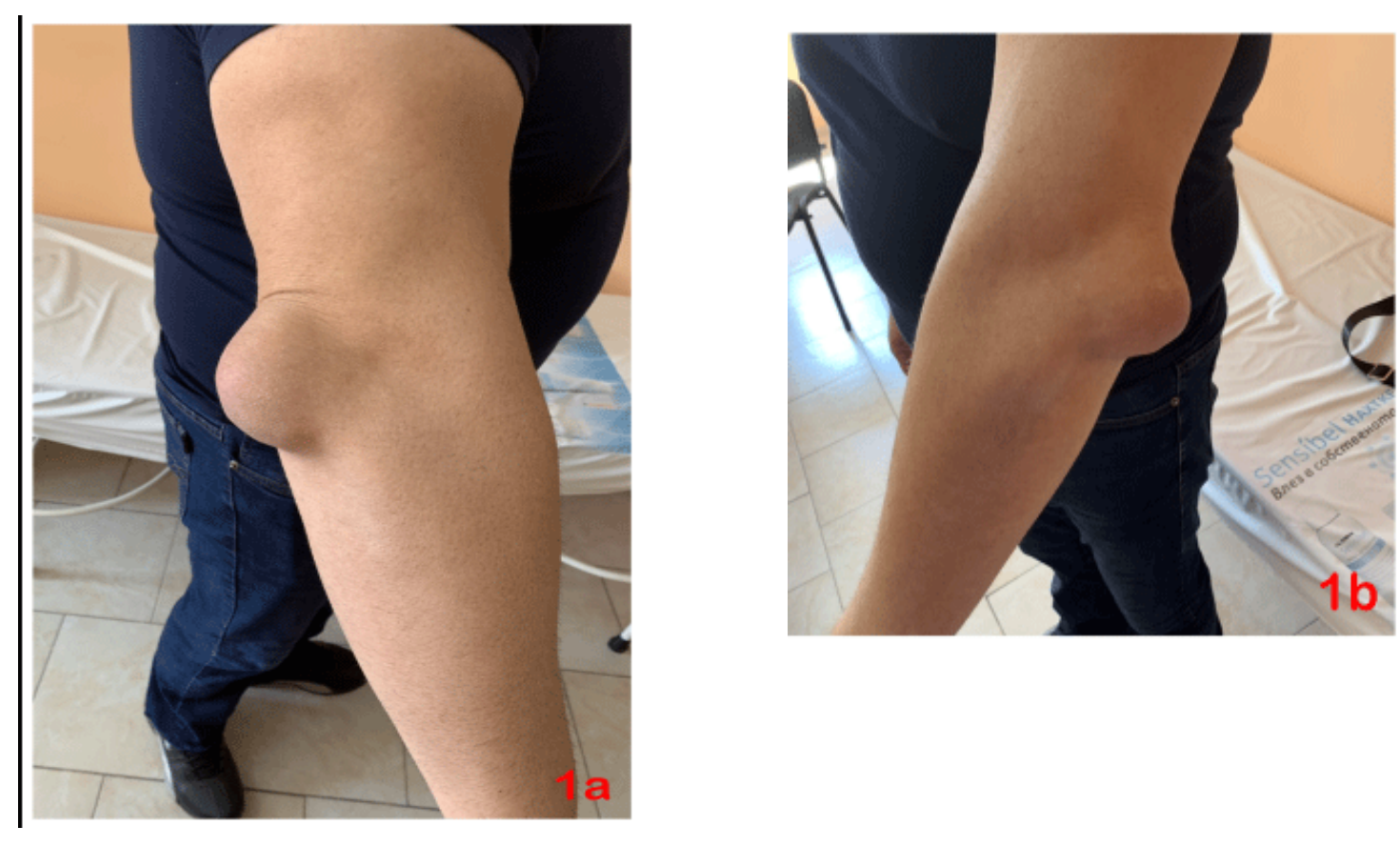

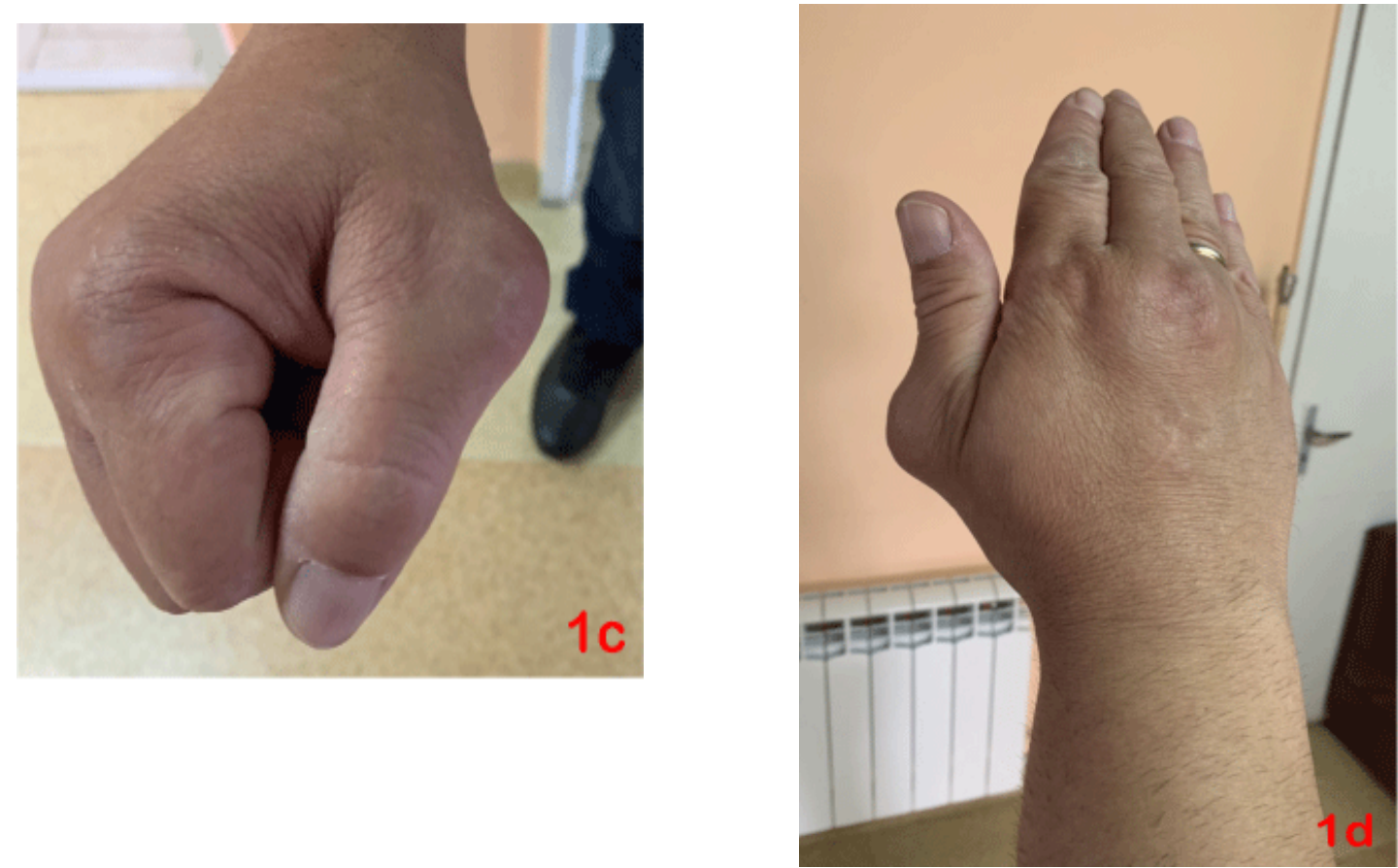

Figure. 1a-1d: Chronic tophaceous gout, with subcutaneous tophi in the area of the two elbow joints and the base of the thumb on the right hand.

In the prevailing number of cases, chronic tophaceous gout frequently occurs after 10 years or more of recurrent polyarticular gout [1]. According to the literature, tophi are rarely observed in patients without a prior history of gouty arthritis [2]. However, the possibility for occurrence of tophi as an initial manifestation of the gout has been described [1, 2]. More interestingly, the available data indicate that large tophi are unusual in chronic gout [1]. The most common areas for gouty tophi localization include helix of the ears, on fingers, toes, wrists and knees, on the olecranon bursae, Achilles tendons [1]. However, there are atypical forms of presentation such as finger pad tophi in the context of chronic Raynaud phenomenon [3]. In these cases, the differential diagnosis of white papules or nodules on the finger pads includes gout, calcinosis cutis, chondrocalcinosis (pseudogout), pyogenic pustules, and oxalosis [3]. In rare cases, gouty tophi may resemble clinically to a viral warts on the soles [4]. It is important to note that usually gout tends to present as articular disease first, and cutaneous gout forming tophi usually correlate with chronicity and uncontrolled disease [4]. These facts determine the need on the one hand to consider the possibility for a tophaceous gout in patients with atypical papules or nodules on the soles and finger pads, and on the other - in cases of established gout, the treatment should be undertaken early in order to avoid the evolution of the disease to the chronic tophaceous form responsible for joint deformities and their functional consequences $[1,4]$.

\section{References}

1. Aradoini N, Talbi S, Berrada K, Abourazzak F, and Harzy T. Chronic tophaceous gout with unusual large tophi: case report. doi:10.11604/ pamj.2015.22.132.6447

2. Shmerling R, Stern S, Gravallese E and Kantrowitz F. Tophaceous deposition in the finger pads without gouty arthritis. Arch Intern Med. 1988;148(8):1830-2.

3. Zarbafian M and Dutz J. Finger pad tophi in a patient with Raynaud phenomenon. JAAD Case Rep. doi: 10.1016/j.jdcr.2016.10.013

4. Bossart S, Sidler D, Blum R and Hunger R. Gout tophi on the soles resembling viral warts. Clin Case Rep. 2018 doi: 10.1002/ccr3.1539 